\title{
PERCEPÇÃO AMBIENTAL DE MORADORES DO BAIRRO DE LIBERDADE DE PARNAMIRIM/RN SOBRE ESGOTAMENTO SANITÁRIO
}

\author{
A. M. C. Bay e V. P. Silva \\ Instituto Federal do Rio Grande do Norte - Campus Natal Central - Curso de Esp. em Gestão Ambiental \\ aurilabio@yahoo.com.br -_valdenildo.silva@ifrn.edu.br
}

Artigo submetido em maio/2011 e aceito em junho/2011

\section{RESUMO}

Estudos sobre percepção ambiental visam investigar as relações que uma sociedade tem com o seu ambiente vivencial, buscando entender fatores, mecanismos e processos que levam as pessoas a terem opiniões e atitudes sobre as mudanças neste ambiente. A implantação de um sistema de esgotamento sanitário melhora as condições ambientais, ao mesmo tempo em que muda a paisagem em torno dos empreendimentos e como consequência mudará a percepção do ambiente pela população. Este estudo analisa a percepção de moradores do Bairro de Liberdade de Parnamirim sobre a implantação do esgotamento sanitário. A metodologia baseou-se em estudos bibliográficos e na aplicação de entrevista. Foram aplicados 30 instrumentos de entrevista, sendo 13 homens e 17 mulheres. A análise dos dados ocorreu por meio de uma abordagem qualitativa, da identificação e valorização dos discursos. Percebeu-se que os moradores do bairro de Liberdade de Parnamirim veem o esgotamento sanitário como mudança na sua qualidade de vida e uma preocupação na diminuição dos impactos ambientais e que ainda existe pouca participação da comunidade para essas mudanças.

PALAVRAS-CHAVE: Percepção Ambiental, Esgotamento Sanitário, Impacto Ambiental, Gestão Ambiental.

\section{ENVIRONMENTAL PERCEPTION OF RESIDENTS OF THE DISTRICT OF LIBERDADE OF PARNAMIRIM SANITARY DRAINAGE}

\begin{abstract}
Environmental perception studies aimed to investigate the relationships that a company has with its environment experiential, seeking to understand factors, mechanisms and processes that lead people to have opinions and attitudes about the changes in this environment. The implementation of a sanitary sewage system improves the environmental conditions, while changing the landscape around the projects and as a result will change the perception of the environment by the population. This study analyze the perception of residents of the Bairro Liberdade the Parnamirim on the establishment of sanitary drainage.
\end{abstract}

The methodology was based on bibliographic studies and application interview. 30 instruments were used to interview 13 men and 17 women. Data analysis was accomplished through a qualitative approach, the identification and recovery of speeches. It was felt that the residents of Liberdade of Parnamirim see the establishment of sanitary drainage as change in their quality of life and concern in the reduction of environmental impacts and that there is still little participation from the community to these changes.

KEY-WORDS: Environmental Perception, Sanitation, Environmental Impact Environmental Management. 


\section{PERCEPÇÃO AMBIENTAL DE MORADORES DO BAIRRO DE LIBERDADE DE PARNAMIRIM/RN SOBRE ESGOTAMENTO SANITÁRIO}

\section{INTRODUÇÃO}

A humanidade tem vivenciado, no curso dos últimos anos, uma crise mundial sem precedentes quanto à exploração de recursos naturais. E em decorrência disso têm surgido inúmeras questões ambientais de grande relevância na atual contemporaneide. Como se sabe, a degradação do meio ambiente vem aumentando, tendo, ao mesmo tempo, seu ritmo acelerado em decorrência de sua apropriação, cada vez mais vem ocorrendo pelo homem, com a finalidade deste, de suprir suas necessidades imediatas ou não. No ambiente urbano moderno, muitos são os aspectos que, direta ou indiretamente, afetam a grande maioria dos habitantes e entre eles podemos citar a pobreza, a criminalidade, a contaminação do solo, da água e do ar etc., além de fatores relacionados como fontes de insatisfação com a vida urbana.

Um dos grandes problemas de degradação urbana que se elegeu como objeto deste estudo foi a ausência de saneamento básico, principalmente do esgotamento sanitário, enfrentado pelas cidades, como decorrência do incremento cada vez maior da urbanização da população.

A falta de sistemas de esgotamento sanitário adequados faz com que a população utilizese de outros meios, como a ligação clandestina de galerias de águas pluviais e o lançamento in natura a céu aberto para lançar seu esgoto doméstico. Essas formas inadequadas de encaminhar os esgotos sanitários trazem sérias conseqüências para o meio ambiente e para a saúde pública, poluindo mananciais e contaminando águas naturais, que nem sempre passam por estações de tratamento eficientes antes do abastecimento público (GIESTA et al, 2005).

A ausência ou a ineficiência desta infraestrutura básica acarreta sérios riscos à saúde, contribuindo para o aumento da ocorrência de diversas doenças, reduzindo assim o tempo produtivo das pessoas, causando óbitos e gerando despesas com hospitalizações e medicamentos, além de criar condições favoráveis à proliferação de vetores ou de insetos indesejáveis.

Os recentes programas do governo federal, com investimentos para a melhoria do saneamento básico, mesmo que incipientes, vêm mudado esse cenário em praticamente todas as regiões do País, principalmente as capitais do Nordeste (BRASIL, 2008) e cidades de porte médio, como é o exemplo do município de Parnamirim, no Rio Grande do Norte.

Como se sabe, a realização de obras para a implantação de esgotamento sanitário melhora as condições ambientais, ao mesmo tempo em que muda a paisagem em torno dos empreendimentos e como consequência muda a percepção do ambiente pela população residente. Nesse contexto, as palavras de Collot (1990, p. 21, grifo do autor), são providenciais, pois nos dizem que, "não se pode falar de paisagem a não ser a partir de sua percepção. Com efeito, [...] a paisagem se define incontinente como um espaço percebido: constitui o aspecto visível, perceptível do espaço". 
Nesse aspecto, a implantação do esgotamento sanitário em bairros da cidade de Parnamirim-RN tem causado uma percepção ambiental equivocada da população em relação ao ambiente que o circunda. Em face da implantação do esgotamento sanitário, lançou-se alguns questionamentos: como os habitantes do bairro de Liberdade da cidade de Parnamirim percebem o meio ambiente vivencial? Qual a percepção que a população tem sobre o meio ambiente e o saneamento básico? As informações fornecidas pelos gestores são suficientes para a população interferir no processo? Existe a participação da sociedade para a implantação do esgotamento sanitário desse bairro?

O município de Parnamirim, recorte espacial de análise deste estudo, tem uma área urbana com extensão territorial de 126,6 $\mathrm{Km}^{2}$, que abriga 22 bairros, conforme mostra a mapa 1 , corresponde a $0,24 \%$ da área do Estado e a $5 \%$ da área da região metropolitana e está localizado no litoral oriental do Estado do Rio Grande do Norte, a $14 \mathrm{~km}$ de distância da capital - Natal, e limita-se ao norte com Natal, ao sul pelos municípios de Nísia Floresta e São José de Mipibu, ao leste pelo oceano Atlântico e ao oeste pelo município de Macaíba. A população estimada em 2007 pelo IBGE foi de 172.598 habitantes, resultando na densidade demográfica de 1.363,3 hab./ $\mathrm{Km}^{2}$.

O Índice de Desenvolvimento Humano Municipal em 2000 foi 0,760 , considerado pelo PNUD como município de médio desenvolvimento humano, ocupando a segunda posição do Estado e a 1571a do Brasil (PARNAMIRIM, 2009). 


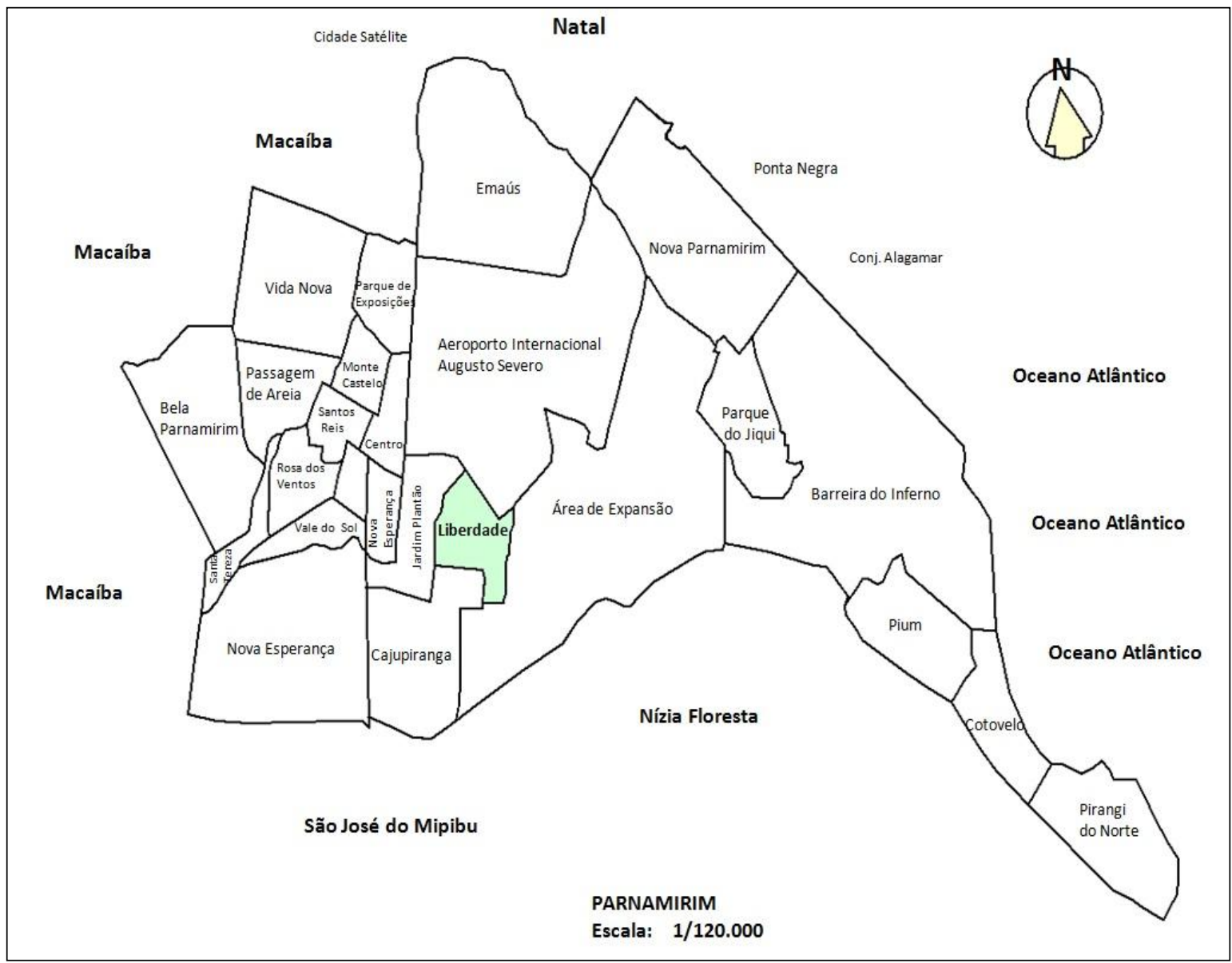

Mapa 1- Desenho representativo dos bairros do município de Parnamirim/RN

O processo de implantação do Projeto de Esgotos Sanitários teve inicio na Comunidade de Pium e das Praias de Cotovelo e Pirangi do Norte, onde começou a ser executado em maio de 2006 (MELO, 2007). As obras fizeram parte do Programa de Desenvolvimento Turístico para o Nordeste (Prodetur II), com investimentos da ordem de R\$18,4 milhões e beneficiou cerca de 40 mil pessoas na região (OLIVEIRA, J.C., 2005).

Com a lei 11.445/07 que estabelece as diretrizes nacionais para o saneamento básico e para a política federal de saneamento básico, cujo um dos princípios é a universalização ao acesso a este serviço e com o Programa de Aceleração do Crescimento (PAC), novos investimentos para a implantação do esgotamento sanitário têm ocorrido em todo o município (BRASIL, 2008).

O PAC em Parnamirim, cujos recursos são do Fundo de Garantia por Tempo de Serviço (FGTS), Fundação Nacional de Saúde e Ministério da Saúde (FUNASA/MS) e Orçamento Geral da União (OGU) e também recursos do município correspondem o valor de $\mathrm{R} \$ 95$ milhões, visa à elaboração do plano de saneamento básico com a implantação do sistema de esgotamento sanitário que atenderá $100 \%$ do município o que hoje representa apenas $0,031 \%$. O projeto apresenta três sistemas de bacias que corresponde a Bacia de Liberdade (Liberdade), Bacia I 
Centro-Oeste (demais bairros) e Bacia II Nova Parnamirim (Nova Parnamirim e Parque do Jiqui). As obras tiveram início em 2008, atendendo inicialmente os bairros de Liberdade, Parque de Exposição, Boa Esperança e Monte Castelo (PARNAMIRIM, 2009).

O estudo em tela centrou-se no bairro de Liberdade (mapa 01) onde as obras se encontram mais adiantadas, cujo recurso é do PAC/FUNASA no valor de $\mathrm{R} \$ 6,4$ milhões. $\mathrm{O}$ bairro possui uma população de aproximadamente sete mil habitantes (IBGE, 2007) e será atendida pelo sistema de ramais condominiais com duas estações elevatórias e uma estação de tratamento de esgoto com o sistema para tratamento de resíduos sanitários pelo processo dos lodos ativos do tipo oxidação total, com previsão para operação do sistema no final do ano de 2009 (PARNAMIRIM, 2009).

O presente trabalho procurou analisar a percepção ambiental da população de moradores do bairro de Liberdade em Parnamirim sobre o programa de esgotamento sanitário que vem sendo implantado. Para tanto, a pesquisa focou sua análise numa abordagem qualitativa, tendo como embasamento as falas e os depoimentos dos entrevistados. Também foi realizado uma pesquisa descritiva da população envolvida e um levantamento bibliográfico. Para que essa análise fosse operacionalizada, elaborou-se um roteiro de entrevista que foi aplicado junto a 30 moradores, tomando por base o "critério de saturação" (SÁ, 1998). Esse critério possibilitou a definição desse número de entrevistados, a partir do momento em que as respostas dadas pelos inquiridos começaram a se repetir, então resolveu-se parar com as entrevistas, pois um maior número de sujeitos pouco acrescentaria de significativo ao conteúdo da percepção ambiental em estudo. Além disso, procurou-se identificar o perfil dos entrevistados, avaliou-se o acesso às informações e a percepção destes quanto ao saneamento e como resultado propor ações que visem à conscientização ambiental e a melhoria da qualidade de vida da população, como uma contribuição da gestão ambiental.

\section{PERCEPÇÃO AMBENTAL E SANEAMENTO BASICO: BREVES APORTES TEÓRICOS}

A percepção ambiental vem sendo estudada em diversas áreas do conhecimento, como na psicologia, geografia, biologia, antropologia e meio ambiente, por exemplo, e busca entender os fatores, mecanismos e processos que levam as pessoas a terem opiniões e atitudes em relação ao meio em que vive. O significado originário do termo percepção expressa à apreensão de um determinado objeto real (BERGMAM, 2007).

A percepção pode ser abordada de duas maneiras: percepção como ferramenta cognitiva - perceber é atribuir um significado, é aquisição de conhecimento - e percepção como algo ligado aos sentidos (SILVA, 2006). 
Sobre a atividade sensorial da percepção essa é dividida em sistemas sensoriais e não sensoriais. $O$ primeiro por meio dos órgãos e os aparelhos que dispomos que nos permitem reter uma parte da informação recebida e o segundo seria através da memória, imagem mental, cultura, experiências, transmissão da informação, orientação geográfica e leitura (OLIVEIRA; MACHADO, 2004).

Oliveira e Machado, com base na teoria de Piaget, afirma que a percepção é encarada como parte integrante da vida do sujeito, sendo uma atividade processual. Por conseguinte, a percepção é o conhecimento que adquirimos através do contato atual, direto e imediato com o objeto e seus movimentos, dentro do campo sensorial. Também de acordo com Piaget, afirma as autoras que "entre a percepção e a inteligência existe uma atividade perceptiva, considerando que a atividade perceptiva é que nos permite: antecipar, comparar, explorar, transpor espacial e temporalmente ou mesmo referenciar". Destacando-se que essas atividades se relacionam à cognição (OLIVEIRA; MACHADO, 2004, p 131, 132).

Outro conceito de percepção é a designação mais específica desse processo, que se constitui em uma operação determinada do homem em suas relações com o ambiente. É a interpretação dos estímulos e a construção de seus significados (BERGMAM, 2007).

\section{Percepção Ambiental}

A importância da pesquisa em percepção ambiental deve-se ao fato de ser uma investigação sobre valores, necessidades, atitudes e expectativas que determinados sujeitos têm em relação ao seu meio vivencial. Essa importância foi ressaltada pela Organização das Nações Unidas para a Educação, Ciência e a Cultura (UNESCO) em 1973 para o planejamento do ambiente.

Soares (2005) apud França (2006) nos diz que uma das dificuldades para a proteção dos ambientes naturais está na existência de diferenças nas percepções dos valores e da importância dos mesmos entre os indivíduos de culturas diferentes ou de grupos socioeconômicos que desempenham funções distintas, no plano social, nesses ambientes.

A percepção ambiental pode ser definida como o produto da reação dos sentidos diante do meio que cerca o individuo, possibilitando o seu raciocínio, a definição de valores, sentimentos, reações e interações positivas ou negativas sobre o ambiente. A partir dessa percepção, o individuo interage com o mundo, influencia seus pares, intervém no ambiente, caminha na direção do processo de conhecimento e do exercício da cidadania ambiental (FERNANDES et al., 2009).

Faggionato (2009) define percepção ambiental como sendo uma tomada de consciência do ambiente pelo homem, ou seja, o ato de perceber o ambiente que se está inserido, aprendendo a proteger e a cuidar do mesmo. Cada indivíduo percebe, reage e responde diferentemente às ações sobre o ambiente em que vive. As respostas ou manifestações daí decorrentes são resultado das percepções (individuais e coletivas), dos processos cognitivos, julgamentos e expectativas de cada pessoa. Desta forma, o estudo da percepção ambiental é de 
fundamental importância para que possamos compreender melhor as inter-relações entre o homem e o ambiente, suas expectativas, anseios, satisfações e insatisfações, julgamentos e condutas.

Embora a sociedade aparente perceber os problemas ambientais, a maioria das pessoas não conhece as origens, conseqüências e formas de enfrentamento desses problemas. Não tendo massa crítica sobre o assunto, a sociedade não percebe os impactos ambientais e sociais a que está submetida e reproduz idéias distorcidas dos mesmos (FERNANDES et al, 2005).

O estudo da percepção ambiental de uma comunidade configura-se em uma ferramenta essencial para a compreensão acerca de comportamentos vigentes e para o planejamento de ações que promovam a sensibilização e o desenvolvimento de posturas éticas e responsáveis perante o ambiente (MARCZWSKI, 2006).

No Brasil, a pesquisa em percepção ambiental vem ganhando espaço no meio acadêmico e nas instituições envolvidas na elaboração de políticas públicas. Destaca-se as pesquisas conduzidas pelo Núcleo de Estudos em Percepção Ambiental (NEPA), sediado em Vitória/Espírito Santo, (MARCZWSKI, 2006) além dos trabalhos que abordam a temática do saneamento e a percepção do ambiente.

\section{Saneamento Básico}

O saneamento básico é um serviço que tem por objetivo principal a manutenção da vida com qualidade através da oferta de água de potável e do desenvolvimento de soluções ao esgotamento sanitário com sua coleta e tratamento. Devendo ser, portanto, um direito de todos, conforme rege a Constituição Brasileira de 1988 (OLIVEIRA, C. F., 2005).

A definição de saneamento baseia-se na formulação da Organização Mundial da Saúde (OMS): saneamento constitui o controle de todos os fatores do meio físico do homem, que exercem ou podem exercer efeitos deletérios sobre seu estado de bem estar físico, mental ou social. O Plano Nacional de Saneamento (PLANASA) em 1971 definiu saneamento básico como apenas as ações de abastecimento de água e esgotamento sanitário. Por outro lado, algumas definições de saneamento ambiental, ao lado das áreas mais clássicas, incluem ações como o saneamento dos alimentos, das habitações e dos locais de trabalho, além da higiene industrial e o controle da poluição atmosférica e sonora, além de ações de esgotamento sanitáriocompreendendo a coleta dos esgotos gerados pelas populações e sua disposição de forma compatível com a capacidade do meio ambiente em assimilá-los (HELLER, 1999).

No caso do sistema de esgotamento sanitário, apesar dos benefícios à saúde pública, com o afastamento dos esgotos da proximidade das residências, existem significativos impactos negativos quando da sua implementação. O principal aspecto negativo desse tipo de sistema, além de possíveis vazamentos, é a concentração da poluição nas redes coletoras. Caso não possua tratamento adequado, o sistema de esgotamento sanitário poderá induzir a uma deterioração do 
corpo receptor (rios, lagos, lagoas, represas, enseadas, baías e mares), inviabilizar a vida aquática e ainda prejudicar outros usuários da água ou outras espécies de animais e vegetais (Pimentel \& Cordeiro Netto, 1998 apud Soares et al, 2002).

O grau de evolução de uma comunidade é identificado pela forma como ela trata seus recursos hídricos e seu lixo. Da mesma forma, identifica-se a seriedade e competência de uma administração pelos esforços em prol do saneamento. Não há saúde sem saneamento (MELO 2007).

O saneamento básico é a medida de saúde pública mais eficiente no tocante de prevenir doenças e reduzir gastos hospitalares. Sabe-se que para cada $\mathrm{R} \$ 1,00$ investido em saneamento economiza-se $\mathrm{R} \$$ 4,00 em medicina curativa. Também é com o saneamento básico que se reduz drasticamente a mortalidade infantil e se aumenta a expectativa de vida de uma comunidade, sendo este um dos fatores componentes do Índice de Desenvolvimento Humano (IDH) de um país (MELO 2007).

\section{PERCEPÇÃO AMBIENTAL DOS MORADORES DE LIBERDADE EM PARNAMIRIM EM RELAÇÃO À IMPLATAÇÃO DO SISTEMA DE ESGOTAMENTO SANITÁRIO}

A análise da percepção ambiental dos moradores do bairro de Liberdade em Parnamirim ocorreu por meio da identificação de seus discursos diante a implantação do sistema de esgotamento sanitário, procurando estabelecer, a partir de suas respostas, uma possível explicação para a nova realidade que estes vivenciam. Segundo Chizzotti (2006, p.121), o discurso é usado pelos sujeitos para explicitar sua identidade (quem sou e o que quero) e sua condição social (com quem estou) e também expor a "ação primordial pela qual constitui a realidade".

As entrevistas foram realizadas com 30 moradores ( 13 do sexo masculino e 17 do sexo feminino), com faixa etária compreendida entre 15 e 67anos, sendo a idade média 36 anos. Quanto ao nível de escolaridade dos entrevistados, a pesquisa revelou que 30\% possuem o Ensino fundamental incompleto, 33,34\% concluíram o Ensino Fundamental, 30\% concluíram o Ensino Médio e apenas $6,66 \%$ são analfabetos.

Os moradores foram inquiridos quanto ao tempo em que residiam no domicilio onde foi realizada a entrevista. Cerca de 6,67\% responderam que moravam a menos de 2 anos, 36,66\% moravam entre 2 e 10 anos, 16,67\% moravam entre 11 e 20 anos e $40 \%$ moravam a mais de 20 anos. Quando perguntados sobre a renda familiar, 33,34\% responderam que recebiam até 1 salário mínimo, 50\% recebiam entre 2 e 3 salários mínimos, 10\% recebiam entre 4 e 6 salários mínimos e 6,66\% recebiam acima de desses valores. Também foram indagados sobre a ocupação, 3,33\% informaram serem funcionários públicos, estudantes, microempresário, desempregado e aposentados respectivamente, 16,66\% disseram ser funcionários de empresas privadas, $26,67 \%$ trabalharam como profissionais liberais e $30 \%$ eram donas de casa. 
Quando perguntados sobre o destino do esgoto de suas residências 90\% dos moradores responderam possuir fossas sépticas, deste percentual $18,52 \%$ possuem sumidouro e $81,48 \%$ destinam água servida em via pública, e 10\% afirmaram não terem fossas em suas residências. Essas respostas constatam a falta de investimento dos gestores públicos em infraestrutura básica e na falta de educação ambiental da população.

Ao serem inquiridos sobre o significado do termo saneamento básico $73,33 \%$ dos moradores mostraram ter algum conceito formulado sobre o termo e $26,67 \%$ não souberam responder. As pessoas que responderam positivamente conhecer o significado do termo se basearam na ausência das fossas, a presença do esgoto nas ruas, o próprio esgotamento sanitário, higienização, como observado no discurso a seguir:

"Seria o esgotamento sanitário."

“Limpeza. As águas escorrem para um conto que é necessário sem poluir”

"Aquele negocio que vai tudo para debaixo da terra."

"Vai limpar mais a água que a gente bebe, evita de criar insetos."

"As águas vão para algum lugar, só não sei onde."

Percebe-se que essas respostas refletem a pouca informação da população em relação ao termo, uma vez que estes apenas se basearam suas respostas na intervenção que a implantação do esgotamento ocasionará no meio em que vivem. Contudo, o termo tem um significado mais abrangente. Segundo França (2006), saneamento diz respeito a um conjunto de ações intersetoriais visando à criação de ambiente urbano saudável, constando principalmente de abastecimento de água, coleta e tratamento de esgoto, drenagem, urbanização e pavimentação, instalações hidrosanitárias, educação sanitária e ambiental, coleta e tratamento de resíduos sólidos, controle de vetores, operação e manutenção dos sistemas.

Os moradores também foram questionados se sabiam a função do esgotamento sanitário no bairro. Destes $80 \%$ afirmaram saber para que serviria a implantação do esgotamento e $20 \%$ responderam não saber a função. Os moradores que responderam conhecer a função $(80 \%)$ argumentaram que o projeto influenciará na higiene, na ausência dos alagamentos e da proliferação de vetores. Para constatar essas influências, apontadas pelos entrevistados, transcrevem-se alguns dos discursos coletados:

"Serve para a cidade ficar limpa e livre dos insetos."

"Tira as porcarias do solo, não polui o meio ambiente."

"Para não ficar tanta sujeira, não tem baratas."

"Evita ficar exposta as lamas nas ruas. O esgoto traz doenças." 


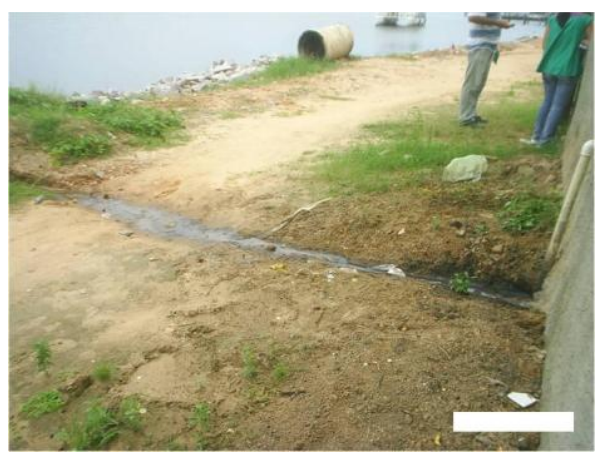

Figura 1 - Água servida lançada no rio Água Vermelha.

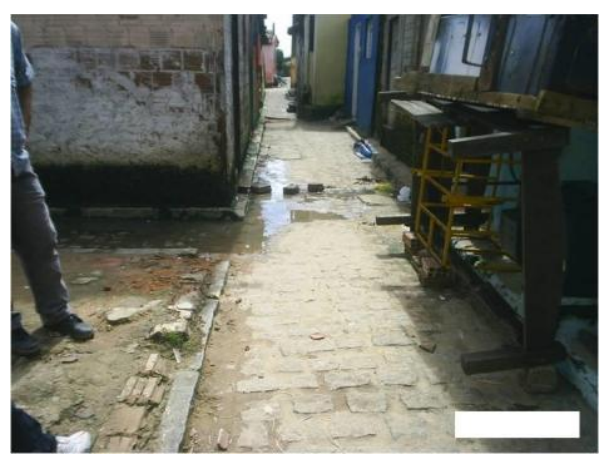

Figura 2 - Água servida lançada em frente as residências.

Por meio dessas respostas é possível perceber que as pessoas apontam a higiene e ausência de vetores como função da implantação do esgotamento no bairro. Vale ressaltar que, essas pessoas, convivem diariamente com as águas servidas (esgoto) na frente suas residências e esgotada no rio Água Vermelha, próximo ao bairro, como mostram as figuras 1 e 2, em decorrência da falta infraestrutura para captação de resíduos líquidos e também que há uma preocupação destes quanto a sua qualidade de vida.

Quando questionados como souberam da implantação do sistema de esgotamento sanitário no bairro, $90 \%$ dos moradores afirmaram terem de alguma forma obtido informações sobre a implantação do sistema, enquanto que $10 \%$ responderam negativamente sabre essa implantação. As entrevistas dos moradores que, afirmam terem tido informações sobre o sistema de esgotamento, apontaram que essas informações deu-se principalmente pelos meios de comunicação (como jornal, rádio e televisão), nos canteiros de obra, a Prefeitura por meio de palestras e aos próprios vizinhos na aquisição das informações, como descritos nestes relatos de moradores expostos a seguir:

"Soube por que vi o povo trabalhando e falando sobre isso."

"Na reunião da comunidade, na associação de moradores que falaram isso."

"Através da Prefeitura, por que tô vendo fazendo."

"O prefeito anunciou na televisão e no rádio."

"Vi os canos e os buracos na rua, os vizinhos comentando."

Diante do exposto, percebe-se que a população teve pouco retorno do poder público quanto às informações sobre a intervenção que haveria sobre o meio que circunda os moradores 
do bairro contemplado. O acesso a informação pela população é um dever do poder público conforme a Lei 11445/07 que estabelece transparência nas ações e sistema de informações sobre os serviços, articulado com o Sistema Nacional de Informações em Saneamento para a população (BRASIL, 2008).

Quanto às entrevistas que responderam não terem tido conhecimento da questão (10\%) mostra certo desinteresse da população diante das questões ambientais e dos aspectos positivos e negativos que estes trazem para o cotidiano:

"Não fique sabendo."

"Eu nem ouvir falar."

Os entrevistados foram questionados quanto à participação no processo de implantação do sistema de esgotamento sanitário no bairro, $16,66 \%$ das entrevistas responderam que sim, afirmando participação na implantação do sistema de esgotamento, enquanto que $83,34 \%$ responderam negativamente a questão. As entrevistas que responderam positivamente $(16,66 \%)$ participaram do processo por meio de reuniões, visitas nas residências, associação de moradores, como observados nas afirmações a seguir:

"Acompanhei o povo quando que ia lá em casa."

"Fui às reuniões."

"O presidente da associação de moradores estava sempre presente nas reuniões."

Por meio dessas respostas, percebe-se um interesse dos moradores, apesar do baixo percentual, em relação à preocupação com o novo cenário em seu entorno. Siqueira (2006) apud França (2006) ressalta que o controle social é a única garantia de acesso universal e equitativo aos serviços de saneamento. Todo o planejamento, a implantação e controle social devem ser regulados e geridos com a participação social, visando à sustentabilidade e a construção da consciência cidadã.

Por outro lado, os moradores que responderam não terem participado da questão, cerca de $(83,34 \%)$, relatam a ausência de tempo e a falta de informação no processo participativo, como em alguns trechos de alguns discursos:

"Não participei por que não fui informado."

"Não tenho tempo e não ouvi falar."

"Não tenho interesse em participar."

"Não fui convidado a participar." 
Diante do exposto observa-se, mais uma vez, que houve a falta de interesse da população e/ou a pouca divulgação por parte do poder público. Segundo Jacobi (1999, p.165) embora exista alguma percepção dos problemas ambientais, geralmente, os moradores aceitam a convivência com esses agravos, assumindo frequentemente uma atitude passiva em face da existência do problema. E também mostra que uma parcela considerável dos entrevistados, ainda não tomou conta e ou se conscientizou da importância das diretrizes constitucionais e do Estatuto da Cidade que preconizam o espaço da gestão social como espaço de voz e visibilidade aos segmentos não visíveis e desfavorecidos da população (FRANÇA, 2006).

Os moradores que foram inquiridos quanto à importância do esgotamento sanitário no bairro, $100 \%$ dos entrevistados responderam positivamente a respeito dessa questão. Esses moradores argumentaram que a implantação do sistema de esgotamento sanitário é importante para evitar o acúmulo de água nas ruas, valorização imobiliária do bairro, diminuição de vetores e doenças. No entanto, alguns não souberam responder sobre a importância do projeto para o bairro. Para validar os pontos apontados como importantes pelos entrevistados segui alguns discursos:

"O bairro fica mais bonito e se valoriza"

"A água não vai ficar acumulada e não vai dar doença (dengue)."

"Por que as águas vão para lá (estação de tratamento) e diminui os mosquitos."

"Evita a poluição do poço de água que é distribuído no bairro."

"Não permite colocar água servida, evita os mosquitos e a poluição, por que a água é tratada."

Essas respostas refletem uma preocupação dos moradores do bairro da Liberdade quanto a sua saúde, tendo em vista a contaminação por infiltração do lençol freático e em decorrência do acúmulo de água, uma vez que o município de Parnamirim apresenta vários casos notificados de denque, além de doenças de veiculação hídrica. E também quanto ao aumento do valor imobiliário das residências, onde a existência de água servida nas ruas prejudica o calçamento, causando transtornos à passagem de veículos e pedestres e por consequência diminui o valor dos imóveis.

Quando inquiridos a respeito das mudanças na qualidade de vida com a implantação do sistema de esgotamento sanitário, $90 \%$ dos entrevistados responderam que sim, afirmando que o sistema de esgotamento sanitário irá melhorar na qualidade de vida, enquanto que $10 \%$ afirmaram negativamente a essa questão. As entrevistas que responderam que a implantação do esgotamento sanitário mudará a qualidade de vida dos moradores apontaram mais saúde e limpeza, e menos poluição e proliferação de vetores como fatores de melhoria. Como observado nas afirmações a seguir:

"Se feito de maneira correta melhora a saúde." 


\footnotetext{
"As ruas vai ficar sempre limpa e as ruas calçadas."

"Não vai contaminar mais as águas."

"Melhora a higiene e o ambiente fica menos poluído."

"Evita que muita água fique no quintal e também os mosquitos."
}

Nessas respostas, percebe-se mais uma vez que a população preocupa-se com as conseqüências que a ausência de um sistema de esgotamento sanitário ocasiona ao bem estar dos habitantes do bairro, além do impacto ambiental que a falta desta infraestrutura adequada proporciona ao meio ambiente local.

Quanto aos entrevistados que responderam negativamente a essa questão, apenas $10 \%$, argumentaram que a ausência do governo, a falta de educação da população e contaminação dos recursos hídricos como fatores que prejudicarão a melhoria na qualidade de vida. Veja as opiniões de alguns entrevistados:

"Dizem que vai cair no rio e a maioria do povo pega água do rio e este vai ficar poluído."

"Depende de o governo fazer e fiscalizar."

"A longo prazo, quando a população se educar."

Por meio desses argumentos, percebe-se a atenção com a qualidade da água e preocupação com a omissão do governo na execução e fiscalização das obras e o desinteresse de proporcionar educação ambiental a população. Citando Jacobi (1999, p163 e 164) a realidade ambiental de uma parte da população está caracterizada pelas dimensões dos problemas, do risco, da falta de informação, resultados, principalmente, da precariedade dos serviços públicos e da negligência e/ou omissão do poder público na prevenção das condições de vida e ao acesso a informação desta população.

\section{CONSIDERAÇÕES FINAIS}

Após as análises das opiniões dos moradores do bairro de Liberdade, em Parnamirim, sobre o sistema de esgotamento sanitário, em implantação, percebeu-se que esses veem o empreendimento como um sistema que trará inúmeros benefícios, como mais higiene, ausências de vetores (mosquitos) em todo o bairro e diminuição da poluição no ambiente, refletindo dessa maneira uma preocupação da comunidade quanto a sua qualidade de vida, além de revelar sujeitos potencialmente ecológicos. 
Em relação à participação dos moradores nesse programa de esgotamento sanitário, viuse que os moradores tiveram pouca integração no processo, apenas $16,66 \%$ dos inquiridos, enquanto a maioria $83,34 \%$ mostrou pouco interesse e se negligenciou a intervir no programa de esgotamento, apresentando uma atitude passiva diante da problemática ambiental, refletindo uma ausência do poder público em mobilizar a participação popular nos projetos implantados no município.

Entretanto, os moradores percebem esse sistema de esgotamento sanitário como melhoria na sua qualidade de vida, apontando um aumento na saúde da população e limpeza do bairro e menos proliferação de vetores como pontos dessa melhoria. De acordo com um dos entrevistados: "O ambiente vai ficar mais saudável, polui menos as águas e melhora a saúde da população", enquanto que para outros: "a qualidade de vida depende da fiscalização do poder público e na educação da população", mostrando a preocupação dos moradores com o bem-estar da comunidade, além do impacto ambiental que a ausência desta infraestrutura ocasiona ao meio local e também da omissão dos gestores públicos em promover campanhas educacionais, voltadas para o meio ambiente e que a população é parte e solução da problemática ambiental.

O desenvolvimento desse trabalho nos possibilitou evidenciar os anseios da população, por meio das falas dos moradores, quanto às mudanças socioambientais que a conclusão desse sistema de esgotamento sanitário proporcionará no dia a dia do bairro de Liberdade. Nesse sentido, o conhecimento da percepção dessa população sobre o meio ambiente e o lugar em que ela vive, permite ao gestor planejar e elaborar projetos em educação ambiental; avaliar, estimular e propor ações mitigadoras dos impactos ambientais; fornecer elementos para as políticas públicas de forma eficaz; mas, nada disso será possível sem a imprescindível e efetiva participação da comunidade nas políticas públicas, nos processos de decisão, planejamento e no controle social. Assim, espera-se que esta pesquisa subsidie a elaboração de campanhas e projetos de intervenção ambiental, envolvendo os sujeitos da sociedade como um todo: população, governo e iniciativa privada.

\section{REFERÊNCIAS}

1. BERGMAN, M. Análise da percepção ambiental da população ribeirinha do Rio Santo Cristo e de estudantes e professores de duas escolas públicas, município de Giruá, RS. 2007. Dissertação (Mestrado em Ecologia)- Instituto de Biociências, Universidade Federal do Rio Grande do Sul. Porto Alegre, 2007. Disponível em:< http://hdl.handle.net/10183/10950>. Acessado em: 12 jan.2009.

2. BRASIL, Ministério das Cidades. Secretaria Nacional de Saneamento Ambiental. Brasília, 2008. Disponível em: <http://www.cidades.gov.br/secretariasnacionais/saneamento-ambiental/acoes/pdf->. Acessado em: 23 fev. 2009.

3. COLLOT, M. Pontos de vista sobre a percepção das paisagens. Boletim de geografia teorética, São Paulo, 20 (39); 21-31, 1990. 
4. FERNANDES, R. S., SOUZA, V. J., PELISSARI, V. B., FFERNANDES, S.T. Uso da percepção ambiental como instrumento de gestão em aplicações ligadas às áreas educacional, social e ambiental. Rede Brasileira de Centros de Educação Ambiental. Rede CEAS. Noticias, $2009 . \quad$ Disponível em: <http://www.redeceas.esalq.usp.br/noticias/Percepcao_Ambiental.pdf> Acessado em: 12 jan. 2009.

5. FAGgiOnATO, S. Percepção ambiental. Material de Apoio - Textos, 2009. Disponível em: < http://educar.sc.usp.br/biologia/textos/m_a txt4.html>. Acessado em: 08 mar 2009.

6. FRANÇA, V. B. V. Percepção ambiental dos membros do 70 Fórum de saneamento e meio ambiente de Penápolis - SP frente à problemática do saneamento. Trabalho de Conclusão de Curso (Especialização)- Programa de Modernização do Setor de Saneamento, Ministério das Cidades. Brasília, 2006. Disponível em: < http://br.monografias.com/trabalhos-pdf/percepcao-ambiental-problematica-

saneamento/percepcao-ambiental-problematica saneamento.shtml>. Acessado em: 05 jan. 2009.

7. GIESTA, J. P.; NETO, C. O. A.; SCUDELARI, A. C. Efeitos da implantação de sistemas de esgotamento sanitário sobre doenças infecciosas e parasitárias em um bairro da cidade de Natal / RN. In: Congresso Brasileiro de Engenharia Sanitária e Ambiental, 23, 2005, Campo Grande. Associação Brasileira de Engenharia Sanitária e Ambiental. Saneamento ambiental Brasileiro: Utopia ou realidade?. Rio de Janeiro, 2005. p.1-9. Disponível em: < http://bases.bireme.br/cgi-bin/wxislind.exe/iah/online>. Acessado em: 01 mar. 2009.

8. GUERRA, R. A. T.; SILVA, C. H. T.; SOUSA, G. U. S. A percepção ambiental de estudantes de ensino fundamental de João Pessoa, Paraíba.Disponível em: <http://www.prac.ufpb.br/anais/meae/Anais II Encontro Tematico/trabalhos/percep cao.doc>Acessado em: 22 fev. 2009.

9. HELLER, L. Relação entre saúde e saneamento na perspectiva do desenvolvimento. Ciência \& Saúde Coletiva, 3(2): 73-84, 1998.

10. JACOBI, P. Cidade e Meio Ambiente. São Paulo: Annablume, 1999.

11. MARCZWSKI, M. Avaliação da percepção ambiental em uma população de estudante do Ensino Fundamental de uma escola municipal rural: um estudo de caso. Dissertação (Mestrado em Ecologia)- Instituto de Biociências, Universidade Federal do Rio Grande do Sul. Porto Alegre, 2006.

12. MELO, K. R. T.; SOUZA, S. C. Ética e gestão ambiental: análise do processo de implantação do projeto de esgotos sanitários da comunidade de Pium e das praias de Cotovelo e Pirangi do Norte, no município de Parnamirim - RN. 2, Congresso de Pesquisa e Inovação da Rede Norte Nordeste de Educação Tecnológica. João Pessoa PB - 2007.

13. OLIVEIRA, J. C. Saneamento e urbanização. Diário de Natal, Caderno Cidades. Natal, p 6, 22 mai.2005. 
14. OLIVEIRA, C. F. A gestão dos serviços de saneamento básico no Brasil. Scripta Nova. Revista electrónica de geografía y ciencias sociales. Barcelona: Universidad de Barcelona, 1 de agosto de 2005, vol. IX, n. 194 (73). Disponível em:< http://www.ub.es/geocrit/sn/sn-194-73.htm>. Acessado em: 04 mar 2009.

15. OLIVEIRA, L.; MACHADO, L. M. C. P. Percepção, cognição, dimensão ambiental e desenvolvimento com sustentabilidade. In: VITTE, Antônio Carlos; GUERRA, Antônio José Teixeira (Orgs.). Reflexões sobre a geografia física no Brasil. Rio de Janeiro: Bertrand Brasil, 2004, p.129-152.

16. PARNAMIRIM. Prefeitura Municipal de Parnamirim. Informações básicas. Disponível em: < http://www.parnamirim.rn.gov.br>. Acessado em: 03 mar. 2009.

17. SÁ, Celso Pereira de. A construção do objeto de pesquisa em representações sociais. Rio de Janeiro: Eduerj, 1998.

18. SILVA, C. M. S. A percepção ambiental de moradores de comunidades carentes - a ZEIS Brasilit. Relatório. Centro Federal de Educação Tecnológica de Pernambuco. Recife, 2006.

1. SOARES, S. R. A.; BERNARDES, R. S; CORDEIRO NETTO, O. M. Elementos para formulação de um modelo de planejamento em saneamento. Caderno de Saúde Pública, Rio de Janeiro, 18(6): 1713-1724, nov-dez, 2002. 